\title{
Medicina Social no Brasil - esboço do perfil de um pioneiro
}

Por ocasião da concessão do título de Professor Honoris Causa desta Escola ao Dr. Hésio de Albuquerque Cordeiro, o Vice-Diretor da ENSP, Prof. Paulo Marchiori Buss, saudou-o com as seguintes palavras:

Minhas senhoras e meus senhores,

Estamos aqui reunidos para homenagear o médico, o professor, o cientista e o amigo Hésio de Albuquerque Cordeiro. A Hésio Cordeiro o Conselho de Ensino, Pesquisa e Extensão da Escola Nacional de Saúde Pública concedeu por unanimidade o título de máximo reconhecimento que lhe é permitido conceder: o de professor honoris causa desta Escola. Esta titulação e esta cerimônia revestem-se de significado especial pelos méritos inegáveis do nosso homenageado, mas também pelo momento histórico que atravessamos com as perplexidades no terreno político, os sobressaltos no campo econômico, e esta imensa dívida social que ainda temos que resgatar.

Impossível apresentar Hésio Cordeiro sem misturar sua biografia com os acontecimentos da história da saúde e do movimento sanitário neste país em anos recentes.

Sua participação na criação do Instituto de Medicina Social da UERJ, suas atividades como professor, pesquisador e, mais recentemente, Presidente do INAMPS, asseguram-lhe um espaço privilegiado nos acontecimentos que marcaram contemporaneamente a saúde neste país.

Nascido em Juiz de Fora/MG no dia 21 de maio de 1942, filho do Dr. Ailton, médico militar e da Dona Yette, mãe carinhosa e amiga, veio cedo, ainda na infância, para o Rio de Janeiro. Freqüentou o Colégio Militar antes de seguir a carreira, digamos, familiar de médico. De fato, seu pai o Dr. Ailton Cordeiro foi clínico por longos anos, até sua morte há 2 anos, e seu irmão Heraldo é médico no interior de São Paulo.

Hésio titulou-se em 1965 na tradicional Faculdade de Ciências Médicas da velha UEG (hoje, UERJ) em Vila Isabel. Durante 5 anos trabalhou como clínico "competente e dedicado" como costuma afirmar e lá encontrou um sonhador, um grande clínico que encarnava a melhor estirpe liberal, o Dr. Piquet Carneiro e dois inquietos: Nina Pereira Nunes e Moisés Szklo. 
$O$ que os unia era um sentimento de profunda insatisfaçăo com as condiçōes da prática médica vigente e a crítica a um sistema de saúde excludente e iníquo que era preciso repensar.

O Brasil começava a viver, então, o pesadelo do regime militar que se estenderia por esses longos 20 anos muito bem conhecidos por todos nós. E sobre aquela pequena experiência pioneira, de medicina comunitária que procurava abrir-se do Hospital para a Favela do Esqueleto - onde hoje estäo os prédios do campus da UERJ - e para o morro dos Macacos, sobre este trabalho ainda incipiente, abate-se um inquérito político-militar que quase o destrói. Entretanto, talvez retirando forças deste primeiro embate, começa tomar contornos mais claros aquela que seria uma das motivaçōes e uma das principais contribuiçōes técnicas do companheiro que hoje homenageamos: este campo de interseção da medicina com as ciências sociais. Hésio sai para formar-se nos Estados Unidos, onde conhece Juan Cesar Garcia. Foi um encontro transformador. De volta ao Brasil - com o apoio de Garcia - Dr. Piquet, Hésio, Nina e Moysés criam o Instituto de Medicina Social da UEG. Junto com o grupo de Campinas, liderado por Arouca, e a ENSP, constitui-se o IMS, desde os primórdios, num dos principais pólos de renovação do pensamento crítico em Medicina Social e de formulaçōes alternativas no campo da política de saúde. A incorporaçăo do social na explicação do processo de saúde-doença, com rigor conceitual e metodológico, foi a grande contribuição do Instituto ao desenvolvimento da Medicina Social no país. A resistência que ofereceu ao regime marcoulhe a face política interna. A proximidade conceitual com o pensamento latino-americano e a solidariedade política com o continente latino-americano varrido pelos golpes e ditaduras deu-lhe a dimensảo, hoje histórica, de casa aberta aos perseguidos e exilados.

Hésio foi sempre professor do Instituto de Medicina Social desde sua criação e lá ocupa atualmente o cargo de Professor Adjunto.

Sua atividade como Professor de Medicina Preventiva e Social se desenvolveu toda naquela Instituição, com ênfase nas áreas temáticas de política e instituições de saúde; assistência médica no âmbito da previdência social; política de medicamentos e tecnologia médica. Foi Coordenador do Mestrado em Medicina Social, no período 1983-1984 e diretor do Instituto de 1983 a 1985.

Tem orientado inúmeras teses no IMS e em outras 
instituições e é responsável pela formação de graude número de quadros técricos -.. muitos dos quais aqui se encontram nesta homenagem - e que ocupam lioje destacadas funçōes nos órgãos públicos de seúde e em instituiçōes universitárias.

Foi professor visitante e colaboracor de diversas instituiçốes nacionais e estrangeiras, inclusive nesta Escola em diversas oportunidades.

Sua atividade como Pesquisador não é menos no. tável. A análise da organização da assistêucia uéfica. com ênfase nas políticas de saúce da Previdência Social brasileira; estudos sobre politica de medicanentes; avaliação de serviços de saúde; e estudos epidemiológicos relativos à determiniayăo socia las Joenças são os principais campos temúticos onde atuia como pesquisador. Desta atividade resultaran inúmeros artigos publicados em revistas nacionais e interuasionais e dois livros, hoje clássicos em seus respectivos cain. pos temáticos e amplanente utilizados no E.asil e na América Latina como referências obrigatơ"as São eles: A Indústria da Saúde no Brasil, publicodo originalmente em 1980 com segunda ediçáo en 1986; e As Empresas Médicas, publicado enn 1984. Säo respectivamente suas teses de Mestrado em Medicina Social, que defendeu no IMS-UERJ em 1979; e de Doutoracio em Medicina Preventiva, que defendeu na Faculdade de Medicina da Universidade de Sáo Paulo, am 1981.

Desde 1972 colabora com a Organizayäo Packamericana de Saúde através de consultorias e assessozias de curto prazo, nos campos da organização dos serviços de saúde, política de saúde e de medicamentos e educação mênica, visitando e atuando em diversos países da América Latina: Argentina, Peru, Equador, Venezuela, Costa Rica, Nicarágua, Honduras, México e República Dominicana.

Este intenso e qualificado trabalbo rendeu-lhe, além dos méritos acúcêmicos e o respeito dos cologias e alunos, também o reconhecimento, digamos, eleitoral. Elegeu-se, em 1983, para uma gestão de 2 anos, como segundo Presidente da história da Associaçāo Brasileira de Pós-Giraduação em Saúde Coletiva, entidade conhecida por todos, que reúne profesadres, pes:quisadores e profissionalis da Saúde Coletiva, de vórias profissöes e camposs disciplinares, além das instituiçöes de pesquisa e formação de recursos humanos de todo - país. Tive a honra de ser o Secretário Executivo da gestĩo de Hésio, que foi acompanhado na dirêtoria, pelos Professores Jose da Rocha Carvalheiro, Francisco Campos e Trinia Nunes. 
Posso testemunhar o salto de qualidade do traba-

lho đa Associação durante a gestão Hésio Cordeiro, nos campos educacionais e de pesquisa. Foi também, este biênio, um momento político especial na vida brasileira. Encerrava-se com as eleiçōes presidenciais de 1984, ainda que indiretas através do Colégio Eleitoral, o ciclo burocrático-autoritário dos regimes militares, mesmo que as forças conservadoras não deixassem - como não deixaram até hoje - o espaço do poder. Aquelas eleiçóes e aquele segmento específico da transição quase-eterna que vamos vivendo permitiu que algumas forças progressistas pudessem expressar-se de forma mais explícita, clara e dinamicamente, reivindicando espaços no poder da denominada "Nova República" que nascia. Hésio, que participara, ainda no período autoritário, dos Simpósios sobre Política de Saúde da Comissão de Saúde da câmara dos deputados, com destacada atuação, passa a integrar Comissões e Grupos de Trabalho para a formulaçăo do programa de Saúde do então candidato Tancredo Neves e, depois, Tancredo já eleito, do Grupo de trabalho para - Programa de Saúde da COPAG (Coordenação do Plano de Ação do Governo), em fevereiro de 1985.

Esta atividade política e uma ampla mobilização de seus companheiros do movimento sanitário de todo país, deu-lhe seguras bases políticas para sua indicação para a Presidência do INAMPS.

Em 21 de maio de 1985, há exatos 3 anos, Hésio assumiu a administração do INAMPS, a mais importante agência de assistência médica da América Latina, se não do 3: mundo. Foi o primeiro sanitarista a ocupar este cargo. Ao professor e ao pesquisador colocou-se o desafio de gerir a grande instituição que ele conhecia de fora, através da abordagem investigativa. Sua primeira providência foi tentar constituir uma equipe coesa, de técnicos competentes e com convergência política para alguns pontos fundamentais. Estiveram com ele, em postos chaves: José Carvalho de Noronha, José Gomes Temporão, Eduardo Levcovitz, Paulo Henrique e tantos outros a quem rendemos também a nossa homenagem. Buscar uma base política e parlamentar sólida foi outro ponto extremamente importante e necessário para dar sustentação a um projeto de mudança que certamente viria a ferir interesses poderosos e há muito tempo instalados em ligaçōes estáveis e auradouras com a tecnoburocracia da previdência. Desalojar corruptos e inviabilizar a continuação dos acordos lesivos ao povo brasileiro e à sua Previdência foram preocupaçōes constantes desde o primeiro mo- 
mento, na direção de construir uma gestão proba e de máximo respeito com o dinheiro público.

Mas a ação política de Hésio e sua equipe não ficou apenas nisso. As Açōes Integradas de Saúde receberam um impulso sumamente importante, passando de 112 para 2800 municípios envolvidos. A destinação de recursos do orçamento da previdência para a saúde, que vinha declinando e se encontrava na faixa de 20 a $21 \%$ em 1984, rompe a barreira dos $30 \%$ no orçamento de 1988. Este incrível patrimônio dos trabalhadores e da população brasileira, que são os serviços públicos, os serviços próprios do INAMPS, começaram a ser efetivamente recuperados, depois de anos de deliberado sucateamento que visava sua aniquilação e substituição total pelos hospitais privados lucrativos. Raras vezes uma instituição compreendeu tão bem o papel da preparação de recursos humanos e do desenvolvimento científico e tecnológico para as ações de saúde, como \& gestão de Hésio no INAMPS. Esta Escola recebeu o decidido apoio do INAMPS para suas atividades de ensino e pesquisa e creio que soube corresponder, com a preparação de mais de 200 profissionais para a Previdência em todo - Brasil, além da cooperação técnica nos campos de sua competência. Dois colaboradores de Hésio a quem desejo lembrar pelo papel que tiveram na realização desse processo são os Drs. Temporão e José Paranaguá Santana.

É na vigência da gestāo de Hésio e sua equipe na Presidência que se realiza a VIII Conferência Nacional de Saúde, em março de 1986, consagrando os princípios mais caros do movimento sanitário, desde suas origens no início dos anos 70 e subseqüentes: a saúde como direito de todos e dever do Estado; a universalização e integralidade na assistência à população; o sistema único, a descentralização e a participação e controle da população como elementos fundamentais a serem alcançados. E lança-se a bandeira ampla, generosa e plena de esperanças de uma Reforma Sanitária capaz de responder às necessidades e aos anseios da populaçāo brasileira.

$\mathrm{Na}$ construção dessa Reforma, um processo que é de todos nós, a gestão de Hésio consegue acrescentar mais uma peça, aquela que consideramos uma decisão corajosa e de grande envergadura política que é a implantação do Sistema Unificado Descentralizado de Saúde - o SUDS. A unificação pela base, buscando superar as controvérsias do órgão único no plano federal. A busca da universalização da assistência, com 
a prioridade dos órgãos e serviços públicos, dos Hospitais Universitários e das Misericórdias e demais órgãos filantrópicos. O esforço de acabar com a figura triste do indigente, a negação máxima da cidadania. A coragem de abrir mão do poder, remetendo-o para uma instância mais próxima da possibilidade do controle social.

É nesse momento em que o INAMPS passa do discurso, da negociação e do esforço do convencimento para a prática efetiva da descentralização, com a assinatura do Decreto do SUDS, em julho de 1987 e a realização dos primeiros Convênios, que as forças conservadoras articulam-se para derrubar Hésio e a proposta do SUDS, pela ameaça que representam aos interesses mesquinhos da politicagem e do filosofismo. A queda se concretizou em 09 de março. As manifestaçōes de repúdio de centenas de entidades da sociedade civil, do movimento sindical, das associaçōes de moradores, do movimento médico, dos movimentos dos trabalhadores dá uma dimensão real das esperanças que se frustraram.

Ontem, o processo continuou com a demissão, que denuncio agora, de dois remanescentes da equipe de Hésio no INAMPS, os companheiros José Gomes Temporão e Eduardo Levcovitz.

Se somarmos a estas medidas a violenta intervenção na política de Saúde Mental, as demissões das sanitaristas em São Paulo, a demissão de Eliza Sá da FSESP e dos Diretores dos Hospitais da área da Saúde Mental no Rio, podemos aquilatar bem a expressão do retrocesso que estamos vivendo.

Entretanto, a história é pródiga de paradoxos. Nesta mesma conjuntura de retrocesso e violência vemos assegurada nas votaçōes desta semana na Constituinte grande parte dos princípios pelas quais vimos lutando historicamente. Fica consignado na Constituição o entendimento da saúde como um direito de todos e dever do Estado, devendo este mesmo Estado assegurar tal direito mediante políticas sociais e econômicas que visem à redução do risco de doença e de outros agravos, além do acesso universal e igualitário às açōes e serviços para a sua promoção, proteção e recuperação. São princípios pelos quais lutamos desde que passamos a conhecer cientificamente as relaçōes entre saúde, estrutura social e condições de vida. Vejo neste princípio uma tese histórica da Medicina Social assegurada na Constituição brasileira. Conquistamos o registro do conceito emblemático do Sistema Único de Saúde e a subordinaçāo dos serviços privados a contratos 
de direito público. A proibição do vergonhoso comércio do sangue foi conquista que devemos registrar, bem como a incorporação da Saúde do Trabalhador, do Saneamento Básico e da proteção ao Meio Ambiente entre as atividades de competência do Sistema Único.

Entretanto, a luta histórica da qual vimos participando não pára aqui, está longe de acabar. Precisamos permanecer mobilizados, porque novos golpes podem estar próximos e é necessário assegurar estas conquistas parciais logo depois da Constituinte na regulamentação do Sistema de Saúde, na lei ordinária que regerá as questōes da Saúde. O trabalho começa já, pois é importante incorporar o maior número possível de segmentos da sociedade neste debate. De outro lado, é necessário erguer barreiras ao retrocesso visível que ameaça o SUDS, esta conquista nossa, materializada pelo INAMPS na gestão Hésio Cordeiro. O CONASS, o Conselho Nacional de Secretários Municipais de Saúde, um grande grupo de Governadores e parlamentares, e amplos segmentos da sociedade civil acreditam neste processo como parte da construção da Reforma Sanitária. No dia de homenagem a um lutador, nada mais coerente que uma conclamação para que permaneçamos lutando.

Hésio, você sempre foi considerado nosso companheiro. Entretanto, hoje, com o título que lhe outorga esta Escola, na decisão unânime de seu Conselho e de toda a comunidade acadêmica, nós podemos dizer com mais força que você é um dos nossos, um professor desta Casa, o que nos enche de júbilo, honra e satisfaçāo. 